\title{
Endothelial Function in Pre-diabetes, Diabetes and Diabetic Cardiomyopathy: A Review
}

Marco Matteo Ciccone ${ }^{1 *}$, Pietro Scicchitano ${ }^{1}$, Matteo Cameli ${ }^{2}$, Annagrazia Cecere ${ }^{1}$, Francesca Cortese ${ }^{1}$, Ilaria Dentamaro ${ }^{1}$, Francesco Gentile ${ }^{3}$, Michele Gesualdo $^{1}$, Maria Maiello ${ }^{4}$, Pietro Amedeo Modesti ${ }^{5}$, Maria Lorenza Muiesan ${ }^{6}$, Salvatore Novo ${ }^{7}$, Pasquale Palmiero ${ }^{4}$, Pier Sergio Saba ${ }^{8}$, Annapaola Zito ${ }^{1}$, Anna Vittoria Mattioli ${ }^{9}$ and Roberto Pedrinelli ${ }^{10}$, on behalf of the Working Group on Hypertension, Prevention \& Rehabilitation of the Società Italiana di Cardiologia

${ }^{1}$ Cardiovascular Diseases Section, Department of Emergency and Organ Transplantation (DETO), University of Bari, Italy

${ }^{2}$ Department of Cardiovascular Diseases, University of Siena, Italy

${ }^{3}$ UOSD Diabetologia Territoriale - ASL BARI, Italy

${ }^{4} A S L B R$, District Cardiology Brindisi, Italy

${ }^{5}$ Department of Clinical and Experimental Medicine, University of Florence, Italy

${ }^{6}$ Department of Clinical and Experimental Sciences, University of Brescia, Italy

${ }^{7}$ Division of Cardiology, University of Palermo, Italy

${ }^{8}$ Division of Cardiology, AOU Sassari, Italy

${ }^{9}$ Cardiovascular Diseases Section, University of Modena and Reggio Emilia, Italy

${ }^{10}$ Dipartimento Cardio Toracico e Vascolare, University of Pisa, Italy

*Corresponding author: Marco Matteo Ciccone, Cardiovascular Diseases Section, Department of Emergency and Organ Transplantation (DETO), University of Bari, piazza G. Cesare,11 - 70124 Bari, Italy, Tel: +39-080-5478791; Fax: +39-080-5478796; E-mail: marcomatteo.ciccone@uniba.it

Rec date: Mar 20, 2014; Acc date: Apr 26, 2014; Pub date: Apr 30, 2014

Copyright: () 2014 Ciccone MM, et al. This is an open-access article distributed under the terms of the Creative Commons Attribution License, which permits unrestricted use, distribution, and reproduction in any medium, provided the original author and source are credited.

\begin{abstract}
Diabetes mellitus worsens cardiovascular risk profile of affected individuals. Its worldwide increasing prevalence and its negative influences on vascular walls morphology and function are able to induce the expression of several morbidities which worsen the clinical conditions of the patients getting them running towards a reduced survival curve.

Although overt diabetes increases the mortality rate of individuals due to its pathogenesis, poor information are in literature about the role of pre-diabetes and family history of diabetes mellitus in the outcome of general population.

This emphasizes the importance of early detection of vascular impairment in subjects at risk of developing diabetes.

The identification of early stages of atherosclerotic diseases in diabetic persons is a fundamental step in the risk stratification protocols followed-up by physicians in order to have a complete overview about the clinical status of such individuals. Common carotid intima-media thickness, flow-mediated vasodilatation, pulse wave velocity are instrumental tools able to detect the early impairment in cardiovascular system and stratify cardiovascular risk of individuals.

The aim of this review is to get a general perspective on the complex relationship between cardiovascular diseases onset, pre-diabetes and family history of diabetes. Furthermore, it points out the influence of diabetes on heart function till the expression of the so-called diabetic cardiomyopathy.
\end{abstract}

Keywords Diabetes; Pre-diabetes; Family history; Diabetic cardiomyopathy; Cardiovascular risk

\section{Introduction}

Diabetes mellitus (DM) is a worrisome health-related problem. According to recent data, the number of person suffering from diabetes mellitus $(\mathrm{DM})$ is expected to double in the next 25 years, passing from the 175 million affected individuals in 2000 to the 353 million in 2030 [1]. The developing countries encounter the major increase in the prevalence of such a metabolic disease [1].
To identify individuals in early stages of DM is fundamental in order to potentially prevent the occurrence of DM and its related, systemic complications. In particular, cardiovascular diseases (CVD) are the leading cause of morbidity and mortality for patients suffering from DM [2]. Atherosclerosis diabetes-related is the major source of CVD in patients suffering from diabetes mellitus types 1 and 2 (T1D and T2D) [3]. The metabolic alterations due to the diabetes are able to impair morphological and functional characteristics of the vascular walls and this condition plays as precursor of atherosclerotic plaques development, thus as the main determinant of the CVD onset [3].

The identification of early stages of atherosclerotic diseases in diabetic persons is a fundamental step in the risk stratification 
protocols followed-up by physicians in order to have a complete overview about the clinical status of such individuals.

The aim of this review is to get a general perspective on the complex relationship between cardiovascular diseases onset, pre-diabetes and family history of diabetes, trying to point out the consequences of such conditions on cardiovascular system and the influence of them on the generation of the so-called diabetic cardiomyopathy.

\section{Pre-Diabetes and Early Impairment in Cardiovascular System}

According to the American Diabetes Association (ADA) the term pre-diabetes is defined as a metabolic clinical condition able to predispose affected individual to a future development of diabetes [4]. Pre-diabetes involves the following two conditions: impaired fasting glucose (IFG) and/or impaired glucose tolerance (IGT). According to biochemical and laboratory parameters and in agreement with ADA guidelines' definitions [4], IFG is defined as a fasting plasma glucose levels ranging from $100 \mathrm{mg} / \mathrm{dL}(5.6 \mathrm{mmol} / \mathrm{L})$ to $125 \mathrm{mg} / \mathrm{dL}(6.9$ $\mathrm{mmol} / \mathrm{L}$ ); IGT as a condition characterized by 2 -h values of plasma glucose in the oral glucose tolerance test (OGTT) ranging from 140 $\mathrm{mg} / \mathrm{dL}(7.8 \mathrm{mmol} / \mathrm{L})$ to $199 \mathrm{mg} / \mathrm{dL}(11.0 \mathrm{mmol} / \mathrm{L})$. Furthermore, a glycated hemoglobin (HbA1C) plasma levels ranging from $5.7 \%$ to $6.4 \%$ is further consider as pre-diabetic condition [4].

According to NHANES (National Health and Nutrition Examination Survey) data [5], the overall IGT prevalence in the United States (U.S.) population over 20 years of age is $13.8 \%$. The prevalence progressively rises with the increase of age. Furthermore, the estimated U.S. prevalence of IFG in adults over 20 years of age was approximately $6.9 \%$ [6].

Several evidences indicate that pre-diabetes conditions may be associated to increased cardiovascular risk profile of individuals [7-10] (Figure 1).

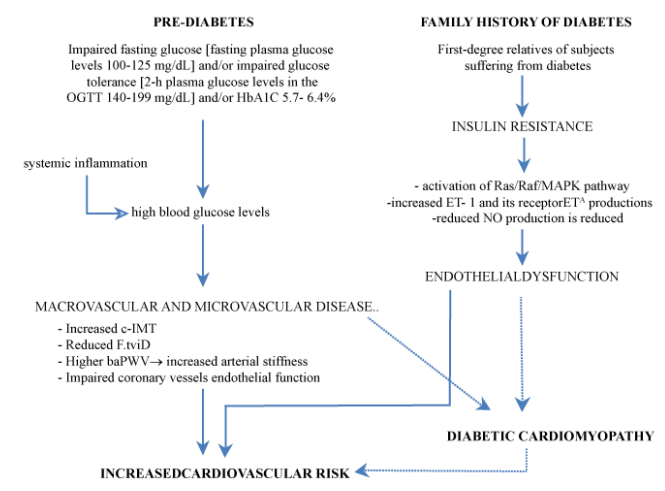

Figure 1: The role of pre-diabetes and family history of diabetes in increasing cardiovascular risk profile of individuals. baPWV: Brachial-Ankle Pulse Wave Velocity; c-IMT: Common Carotid Intima-Media Thickness; FMD: Brachial Artery Flow Mediated Vasodilation; ET-1: Endotelin-1; HbA1C: Glycated Hemoglobin; MAPK: Mitogen-Activated Protein Kinase; NO: Nitric Oxide; OGTT: Oral Glucose Tolerance Test

Shah et al. [7] recently demonstrated that obese young patients suffering from pre-diabetes were more prone to show increased common carotid intima-media thickness (a well-known early marker of atherosclerosis) than obese youth with normal glycemic control. Apart from the morphological alterations in systemic vascular beds, pre-diabetes is effectively able to worsen the performance of coronary vessels which increases the overall cardiovascular risk of individuals. Erdogan et al. [9] evaluated the coronary flow reserve (CFR) in prediabetic, diabetic and normal glycemic patients. The pre-diabetic condition was able to impair the endothelial function of coronary vessels (percentages of pre-diabetic patients with CFR $<2 \%$ : $17 \%$ vs percentages of normal subjects with CFR $<2 \%: 5 \%$, p $<0.05$ ) [9]. Such results were maintained even after adjusting for confounding factors, revealing diabetes as a real predictor of CFR impairment $(\beta=-0.57$, $\mathrm{p}<0.01$ ). A meta-analysis from Levitan et al. [10] pointed out that effectively pre-diabetic condition is able to increase the cardiovascular risk profile of individuals. When considering non-diabetic hyperglycemic patients, those showing the highest fasting blood glucose concentrations had a relative risk equal to 1.27 [95\% confidential interval (CI), 1.09-1.48] to develop cardiovascular diseases [10]. Multivariable regression analysis continued to confirm the results as it pointed out a relative risk equal to 1.19 (95\% CI, 1.07-1.32) to develop cardiovascular events [10].

Therefore, IFG and IGT should be considered risk factors for the development of diabetes and conditions associated with the development of macrovascular and microvascular disease (Figure 1).

The pathogenesis of the vascular impairment in pre-diabetic conditions is particularly intriguing. It is known that two metabolic defects occur in most patients suffering from T2D: insulin resistance and/or insulin secretion deficiency. The consequence of the impaired insulin secretion from pancreatic beta cells can be due to a loss of beta cells or impairment in the beta cell function.

All these conditions leading to diabetes may occur at a lesser extent in course of pre-diabetes [11]. Most of people suffering from prediabetes often reveal insulin-resistance [11]. Such situations negatively influence systemic healthy conditions of individuals above all due to the hyperglycemic state induced by impaired pancreatic beta-cells function or by the peripheral cell resistance to insulin. Incretins' alterations are also involved in the pathogenesis of pre-diabetes and type 2 diabetes. Incretins are hormones produces by enteroendocrine $\mathrm{L}$ cells of the small and large intestine [12]. The two major representative hormones of such a family are glucose-dependent insulinotropic polypeptide (GIP) and glucagon-like peptide-1 (GLP-1) and they are able to exert an important role on beta-/alpha-cells of pancreatic islet and on several structures and cells widespread in the organism [12]. Their main action is to potentiate post-prandial augmentation of insulin secretion from pancreatic cells. In particular, they seem to mediate about $50-70 \%$ of the overall insulin response after a mixed meal or glucose ingestion in healthy subjects [12]. Therefore, alterations involving the synthesis, the secretion process, the interactions of these hormones with their receptors and the transduction of the signal mediated by the coupling between incretins and their receptors are all conditions related to the development of pre-diabetes and later of frank T2D onset $[13,14]$. Unfortunately, incretins' impairments are able to exert negative roles on heart and vessels: the relative insulin-resistance induced by incretins' reduced production/action impairs the energy availability of the myocardium, condition that can worsen heart function [15]. Furthermore, the transduction of the signal through their receptors makes the incretins to enhance the mitogen-activated protein kinase (MAPK) pathways: the relative biochemical pathways are able to activate functions which 
promote improvements in cardiac function and protection towards ischemia [15]. Finally, incretins mediate the nitric oxide/cyclic guanosine monophosphate (cGMP)-dependent pathway in the vascular endothelial cells: this is fundamental in order to explain the endothelial dysfunction related to incretins' impairments in their action and the vascular walls morphological and functional damages often observed in case of pre-diabetes [15].

Hyperglycemia appears to directly impair endothelial cells function and morphological structure $[16,17]$. The molecular mechanisms are not fully understood although several hypotheses tried to explain this relationship. Several mechanisms are involved and have a common denominator: oxidative stress and reactive oxygen species' creation. Hyperglycemia, in fact, is able to activate protein kinase $\mathrm{C}$ which is able to enhance nicotinamide adenine dinucleotide phosphate (NADP) oxidase action, thus promoting the genesis of reactive oxygen species (ROS) and, consequentially, oxidative stress $[18,19]$. The same happens after the production of the advanced glycation end (AGE) products which are compound able to increase NADP oxidase activity and ROS generation and to augment tissue factor release, i.e. a molecule able to enhance coagulation processes. Moreover hyperglycemia is able to increase the flux through the hexosamine pathway and to induce the polyol pathway, all conditions related to a further ROS generation and finally to induce over-expression of growth factors and inflammatory cytokines [16,17].

Furthermore, beyond oxidative stress, hyperglycemia is able to impair and uncouple endothelial nitric oxide (eNOS) activity [16]. Such an impairment is dangerous because predisposes to endothelial dysfunction, which is a well know early marker of atherosclerosis and increased cardiovascular risk [20,21].

Despite such evidences, the interaction between hyperglycemia, pre-diabetes and vascular impairment is more complex. Literature studies disagreed with the theory of hyperglycemia as directly able to induce vascular lesions $[22,23]$. The theory proposed in the last years sustained the reciprocal interaction between inflammation and high blood glucose concentrations as the basic synergism able to increase the damages and to promote atherosclerosis. Azcutia et al. [22] demonstrated that it is necessary a pro-inflammatory vascular condition in order to potentiate the expression of adhesion vascular molecules and other inflammation-related compounds able to enhance the atherosclerotic process. The authors, in fact, demonstrated that pre-diabetic condition was not able to induce the expression of intercellular adhesion molecule-1 (ICAM-1) and vascular cell adhesion molecule-1 (VCAM-1) [22]. Furthermore, high glucose levels were able to enhance the in vitro expression of extracellular signal-regulated kinase $1 / 2$ (ERK 1/2) and nuclear transcription factor$\mathrm{kB}$ (NF-kB) (i.e., well-know activator of adhesion molecules) only when interleukin $1 \beta$ (IL-1 $\beta$ ) was present [22]. These results confirmed those coming from Rasmussen et al. [23] demonstrating no increasing in adhesion molecules VCAM-1 and E-selectin expression on activated endothelial cells in patients suffering from diabetes and pre-diabetes. Nevertheless, Lucas et al. [24] recently demonstrated the higher concentrations of serum cytokines [IL-5, IL-6, IL-7, tumor necrosis factor- $\alpha$ (TNF- $\alpha$ ), and granulocyte-monocyte colony-stimulating factor (GM-CSF)] in pre-diabetic patients as compared to matched controls. The combination of systemic inflammatory condition and high blood glucose levels is the mixture for the atherosclerosis development: apart from the increase in adhesion molecules concentrations, pre-diabetes and inflammatory condition are associates to plasma asymmetrical dimethyl-l-arginine (ADMA) thus to the development of early endothelial dysfunction in such individuals [25-27].

It is supposed a role of hyperglycemia and pre-diabetic condition in enhancing deposition of extracellular matrix (ECM) proteins: the consequence is a progressive thickening of the internal and external elastic membrane of the vascular walls and an increasing in vessels' stiffness [16]. Pericyte loss, capillary microaneurysms and vascular proliferation are further vascular alteration observed in pre-diabetic individuals $[16,17]$.

Brownlee [28] optimally unify such theories in its work where all the aspects of vascular impairment due to altered glycemic control are expressed. All these changes in vascular wall represent the beginning of a complex condition named microangiopathy. Therefore, prediabetes is strictly related to microangiopathy although, at the best of our knowledge, physicians have no laboratory indicators able to detect this early alteration before their clinical expression.

Microalbuminuria may be considered among indicators: the prevalence of microalbuminuria is approximately 2 -fold higher in subjects suffering from pre-diabetes than controls [29]. The chronic and subclinical inflammation due to the hyperinsulinemia and/or insulin resistance which characterizes pre-diabetes, accounts for the use of circulating levels of proinflammatory molecules such as Creactive protein (CRP) as potential marker of subclinical expression of pre-diabetes and its microangiopathic lesions [30-32]. Finally, the number of endothelial progenitor cells (EPC), well-established marker of early impairment in vascular function, increase in patients suffering from pre-diabetes [33].

Nevertheless, the consistence of such relationships is really poor and not standardized. Thus, instrumental evaluations should be performed [20]. The aim is to point out the early stages of morphological and functional alterations of vascular wall which are the background of more severe microangiopathic lesions [34,35].

Altered fasting glycemia contributes to impaired vascular function in non-obese subjects [35]. In particular, Liu et al. [36] recently considered 61 patients (mean age: $49.8 \pm 4.8$ years) suffering from IGT. The enrolled patients underwent endothelial function evaluation. They were assessed for endothelium-dependent (by means of reactive hyperemia after cuff desufflation) and -independent (by means of 0.4 mg sublingual nitroglycerin administration) vasodilation of the brachial artery. Although the study was limited by the small sample size, the authors pointed out a significant reduction in endotheliumdependent vasodilation properties of brachial artery of pre-diabetic patients as compared to controls. No differences of endotheliumindependent vasodilation were found [36]. Su et al. [37] considered 133 individuals suffering from IGT and IFG and they confirmed that flow-mediated vasodilatation (FMD) of the brachial artery was impaired in pre-diabetic patients.

Another early indicator of atherosclerosis is carotid intima-media thickness (c-IMT) [38,39]. Hulya et al. [40] found higher c-IMT in pre-diabetic patients as compared to controls. Shah et al. [7] considered 102 young obese suffering from pre-diabetes. Pre-diabetic patients showed increased c-IMT as compared to controls $(\mathrm{p}<0.05)$, even after adjusting for confounding factors. Same results came from Faeh et al.'s [41] study. They observed significant differences between IGF/IGT and controls in terms of c-IMT $(0.71 \pm 0.01 \mathrm{~mm}$ vs $0.76 \pm$ $0.02 \mathrm{~mm}$; for trend: $\mathrm{p}<0.001)$, even after adjusting for age and sex. 
Pre-diabetes could impair arterial compliance due to the thickening process and loss of elasticity of the arterial walls. Measurement of arterial stiffness is considered a useful surrogate marker for early-stage atherosclerosis detection [20]. Shen et al. [20] showed that brachialankle pulse wave velocity (baPWV), an early marker of atherosclerosis, was significantly higher in subjects with $\mathrm{HbA1C}$ between $5.7 \%-6.4 \%$ and IFG as compared to subjects with normoglycaemia [42]. These results presented additional evidence to support the hypothesis that early development of adverse vascular changes already existed prior to the development of overt diabetes, suggesting that the strict glycemic control in pre-diabetic subjects might achieve a positive long-term protection against atherosclerosis. Shin et al. [43] found that highnormal glucose group had higher mean baPWV than those of the lownormal glucose group $(1328 \pm 167 \mathrm{~cm} / \mathrm{s}$ vs $1303 \pm 196 \mathrm{~cm} / \mathrm{s}, \mathrm{P}<0.05)$; the same was for the IFG group mean baPWV as compared to controls $(1469 \pm 220 \mathrm{~cm} / \mathrm{s}$ vs $1303 \pm 196 \mathrm{~cm} / \mathrm{s}, \mathrm{P}<0.05)$. Multivariate regression models confirmed these results [43].

Despite such claims, controversies still persist on whether fasting glucose is able to directly impair endothelial function or not. In particular, concerns are about the different impact of glycemic control on micro and microangiopathy that feed the controversies about the influence of glucose on endothelium. Experimental models from Cherian et al. [44] involving diabetic rat outlined that a tight glycemic control was able to reduce the basement membrane thickening in retinal and glomerular capillaries and fibronectin over-expression at the same level. This meant that tight glycemic control might positively influence microangiopathy development. Such conclusions are in contrast with those coming from Shurter et al. [45] who observed a progressive worsening of diabetic retinopathy in case-control study involving type 2 diabetes. In particular, the authors observed that a tight glycemic control improve the progression of retinopathy from baseline $(+0.7+0.25$ units, $\mathrm{p}=0.015)$, while the standard glycemic control group did not showed any significant change in the progression of their eye disease as compared to baseline $(0.03+0.14$ units, $\mathrm{p}=$ NS) [45]. Chilelli et al. [46] proposed a "glycoxidationcentric" theory: rather than glycemic control, AGEs control is the best way to reduce the burden of microangiopathy in diabetic patients. A United Kingdom Prospective Diabetes Studies (UKPDS) subevaluation [47] pointed out that a tight glycemic control was able to induce a $37 \%$ decrease in microvascular complications' occurrence ( $33 \%$ to $41 \%, \mathrm{P}<0.0001$ ). Similar results came from the analysis of T1D patients [48]: a sub-study analysis from the Diabetes Control and Complications Trial (DCCT) and Epidemiology of Diabetes Interventions and Complications (EDIC) revealed that intensive glycemic control was associated to a statistically significant $(\mathrm{P}<0.001)$ slower rate of reduction in the glomerular filtration rate (GFR) and a statistically significant $(\mathrm{P}<0.001)$ increase in the mean estimated GFR of $2.5 \mathrm{ml}$ per minute per $1.73 \mathrm{~m} 2$ as compared to normal intensive glycemic control [48]. Nevertheless, further studies are needed in order to better evaluate the role of tight glycemic on diabetic microangiopathy.

The literature results remain unclear even when considering the macrovascular expression of diabetes-induced alterations. Referring to UKPDS sub-research [47], the authors observed a $21 \%$ for deaths related to diabetes $(15 \%$ to $27 \%, \mathrm{P}<0.0001)$ and a $14 \%$ reduction in myocardial infarction ( $8 \%$ to $21 \%, \mathrm{P}<0.0001)$ in intensive control group. A recent meta-analysis [49] elegantly tried to overcome the issue of tight glycemic control in macrovascular alterations induced by diabetes. The data from the major international clinical trial about such a matter [i.e. Action to Control Cardiovascular Risk in Diabetes
(ACCORD), Action in Diabetes and Vascular Disease: Preterax and Diamicron Modified Release Controlled Evaluation (ADVANCE), UKPDS and Veterans Affairs Diabetes Trial (VADT)] had been analyzed by the authors. The analysis revealed that intensive control was able to reduce the incidence of the overall major cardiovascular events (cardiovascular death or non-fatal stroke or non-fatal myocardial infarction) by $9 \%$ (HR: 0.91, 95\% CI: 0.84-0.99). Although such statistical significance was maintained for non-fatal/fatal myocardial infarction (hazard ratio (HR): 0.85, 95\% CI: 0.76-0.94), when there were analyzed the risk reduction of non-fatal/fatal stroke and the hospitalization for heart failure, the intensive fasting glucose control was not able to exert a positive role and lose the previous significance (HR: 0.96, 95\% CI: 0.83-1.10 and HR: 1.00, 95\% CI: $0.86-$ 1.16 , respectively) [49]. The authors supposed that such differences in the results were led by the presence of previous history of macrovascular disease at randomization: those with prior macrovascular diseases were less responsive to intensive glycemic control as compared to those with no prior macrovascular diseases. Nevertheless, more evidences are needed in order to confirm or not such data.

\section{Vascular Walls Modifications in Subjects with Family History of Diabetes}

The pre-diabetic condition is related to increased cardiovascular risk profile of affected individuals [50], as demonstrated by several studies which revealed the impairment in early markers of atherosclerosis due to pre-diabetes [51,52]. Insulin resistance is one of the main features characterizing T2D and some studies pointed out that it sometimes is a heritable trait [53]. Newmann et al. [54] demonstrated that T2D is strongly genetically determined. This information outlines a peculiar aspect of the complex clinical picture of diabetes and its role on individuals' prognosis: the role of family history of diabetes in the overall incidence of cardiovascular events. Such an aspect is often misunderstood in the clinical assessment of apparently healthy patients.

First-degree relatives of subjects suffering from T2D show the metabolic features of insulin resistance before they develop overt diabetes [55]. Straczkowski et al. [56] demonstrated that insulin resistance is present even in young lean subjects at high risk to develop T2D. They compared 17 lean subjects with family history of T2D (first degree-relatives affected) to 17 matched controls showing no family history for T2D. Results outlined that the former were more hyperinsulinemic and insulin-resistant than controls $(\mathrm{p}<0.05$ and $\mathrm{p}<0.005$, respectively). They supposed that insulin resistance might account for primary abnormality in the pathogenesis of diabetes in predisposed subjects [56] (Figure 1).

Furthermore, the increase in insulin blood concentration can induce by itself an overall increase in the vascular impairment. The presence of insulin resistance and insulin itself are able to directly impair the function of endothelial cells as outlined in previous studies $[57,58]$. It is known that the interaction between insulin and its endothelial cells' receptor is able to activate several biochemical pathways: 1) insulin receptor substrate-1 (IRS-1)/phosphatidylinositol 3-kinase (PI3K), related phosphorylation of Akt and activation of eNOS, thus progressive increase in nitric oxide $(\mathrm{NO})$ production and consequent vasodilatation; 2) activation of Ras/Raf/MAPK pathway whose ultimate action is the generation of endotelin-1 (ET-1), i.e. a molecule involved in the vasoconstriction, and its own receptor, ETA $[57,58]$. Insulin resistance redirects the pathways activation towards 
ET-1 production: in these conditions, the endothelium is not able to perform its normal function, the NO production is reduced and vasoconstriction prevails [57,58]. The final step is endothelial dysfunction which is a well-known early marker of atherosclerosis. Furthermore, it was demonstrated that high concentrations of insulin are able to promote atherosclerosis due to in vitro increased expression of adhesion molecules on endothelial cells due to the presence of such a hormone: this is the first step for monocytes migration into the intima and to their transformation in foam cells $[57,58]$. This enhances the atherosclerotic process.

Family history of diabetes mellitus is not only related to a pure increase in metabolic alterations predisposing to the onset of overt diabetes but it seems to overcome the endocrinological alterations and to provoke early lesions even in the vascular walls. Thus, family history of diabetes increases cardiovascular risk profile of individuals. Although this is not supported by strong scientific evidences, many observational studies revealed its relationship with increased cardiovascular risk.

For example, Balletshofer et al. [59] measured endotheliumdependent and -independent vasodilation of the brachial artery in 53 normotensive and normoglycemic first-degree relatives of patients with T2D. They found a significant endothelial dysfunction in such a category of individuals, independently of the classic cardiovascular risk factors. Goldfine et al. [60] confirmed the impaired vascular function in subjects with parents suffering from T2D. In particular, they evaluated endothelial-dependent vasodilation (by means of hyperemia cuff deflation) and endothelial-independent vasodilation (determined after nitroglycerin $0.4 \mathrm{mg}$ sublingually administration). Endothelial-dependent vasodilation was $38 \%$ lower in individuals with family history of T2D as compared to controls $(7.1 \pm 0.9 \%$ vs. $11.7 \pm$ $1.65, \mathrm{p}<0.02)$. No difference was according to endothelialindependent vasodilation.

These results are in agreement with those from Scuteri et al. [61]. These authors found that normotensive normoglycemic first-degree relatives of diabetic subjects showed a $33 \%$ decrease in endothelium dependent vasodilation as compared to controls $(9.8 \pm 5.2 \%$ vs. $16.2 \pm$ $7.6 \%, \mathrm{p}<0.019)$. Such result was independent of insulin-resistance conditions of the subjects. Nevertheless, Lee et al.'s [62] results contrasted all of these. In fact, they measured microvascular hyperemia induced by heat locally applied to skin by means of laser Doppler-flowmetry in 21 patients with family history of T2D. Results pointed out that skin maximum and minimum microvascular hyperemia did not statistically differ between patients and controls ( $\mathrm{p}=0.99$ and $\mathrm{p}=0.70$, respectively).

Furthermore, Scuteri et al. [61] found that arterial stiffness, measured by means of carotid-femoral PWV, was significantly increased only in first-degree relatives of diabetic subjects. This confirmed studies reporting a reduced aortic compliance in patients with family history of diabetes [63].

Apart from endothelial function impairment, family history of diabetes alters vascular morphology of the vascular walls. Pannacciulli et al. [64] evaluated c-IMT in 188 individuals aged 18-45 years with normal glucose tolerance and family history of T2D. They demonstrated that c-IMT was higher in first-degree family history of T2D as compared to controls $(0.84+0.01 \mathrm{~mm}$ vs $0.77+0.01 \mathrm{~mm}$, $\mathrm{p}<0.001)$. In the multiple regression model, $\mathrm{c}$-IMT continued to be significantly associated with family history of T2D $(\mathrm{p}<0.01)$.
Anderwald et al. [65] compared the role of family history of T2D and of cardiovascular disease on vascular morphology assessed by means of c-IMT. They considered 1048 patients subdividing them in four groups according to family history: 1) patients with T2D family history; 2) patients with family history of cardiovascular diseases; 3 ) patients with both family history conditions; 4 ) patients with no family history. Results found no relationship between c-IMT and family history of T2D, while only cardiovascular diseases offspring showed significant relationship.

These results were in contrasts with previous research from Anderwald et al. [66] which pointed out that internal carotid artery intima-media thickness was $18 \%$ higher in T2D offspring than controls. Same results came from Ahmad et al. [67] because they demonstrated a higher c-IMT in patients with first degree relatives suffering from T2D, but adjustment for confounding factors did not confirm the first findings.

Several hypotheses have been generated in order to explain such relationship between family history of diabetes and cardiovascular risk profile of individuals. Family history of diabetes increases per se the risk of coronary heart disease even in non-diabetic subjects [68]. This may be due to an increased prevalence of abdominal fat content in such subjects [69], to elevated systolic blood pressure, higher triglyceride and cholesterol plasma concentration [70], higher plasminogen activator inhibitor-1 activity [71]. All these conditions could increase the cardiovascular risk profile of individuals and lead them to be considered as a "risk population" even considering their apparently "healthy" general clinical condition.

\section{Diabetic Cardiomyopathy: Pathophysiology and Diagnostic Evaluation}

Diabetes increases the risk of developing heart disease by severalfold, while more than half of all diabetic patients develop coronary heart disease and/or hypertension [72,73]. Heart involvement in diabetes goes beyond the damage to coronary arteries due to the progress of atherosclerotic process. Diabetes and its pathophysiological consequences are able to induce direct alterations and abnormalities in the cardiac muscle functions. Such dysfunctions lead to impairment in cardiac contractility and ventricle compliance which create the condition called "diabetic cardiomyopathy". The terms "diabetic cardiomyopathy" were initially introduced in 1972 by Rubler et al. [74] in order to define structural and functional abnormalities in the myocardium of diabetic patients without coronary artery disease or hypertension [74,75] (Figure 1). Multiple mechanisms were supposed to generate such a disease and they include: alterations in cell survival pathways, extracellular matrix increased formation, post-translation protein modification and glucose metabolism.

\section{Inflammation and cardiac insulin resistance}

Diabetes is associated to chronic low-grade inflammation and to increased secretion and activation of pro-inflammatory adipokines and cytokines $[76,77]$. These pro-inflammatory molecules contribute to cardiac insulin resistance because they mediated the phosphorylation of the serine of the IRS-1 [77]. The alterations in such a biochemical pathway are crucial for the cardiac cells. IRS-1 is a critical molecule in the cardiac insulin signaling pathway: its pleckstrin-homology $(\mathrm{PH})$ domain facilitates the binding to the phosphorylated insulin receptor, while its $\mathrm{SH} 2$ domain allows PI3K 
activation [78]. PI3K phosphorylates protein kinase B (Akt) ultimately leading to the translocation of the glucose transporter 4 (GLUT4) at the cardiomyocyte cell surface, thus facilitating glucose uptake [79]. TNF- $\alpha$ is also implicated in the induction of cardiac insulin resistance. It activates NF- $\mathrm{kB}$ as well as the redox-sensitive Ser C-Jun N-terminal kinase (JNK): such activations induce phosphorylation of the serine of IRS-1, which targets such a molecule to the degradation via ubiquitin pathway $[80,81]$.

\section{Structural and functional changes in the heart as a result of diabetes}

Several molecular signaling pathways are implicated in the development of cardiac dysfunction in diabetes individuals $[82,83]$. Hyperinsulinemia, hyperglycemia and insulin resistance increase oxidative stress which may account for the initial damages to cardiac cells $[84,85]$. Furthermore, the increased circulating free fatty acids (FA) and altered lipids metabolism induce FAs accumulation and lipotoxicity in the heart [86].

These events firstly induce a diastolic dysfunction which precedes the development of systolic one $[83,87]$. In particular, the diastolic dysfunction leads to progressive fibrosis, impaired calcium handling in the heart and, thus, to contractile dysfunction, cardiac autonomic neuropathy and increased mitochondrial and endoplasmic reticulum stress contributing to the reduced cardiac energy load $[82,83]$.

Furthermore, all these alterations are able to macroscopically affect the heart. Diabetic cardiomyopathy is effectively characterized by a disproportionate increase in left ventricular mass and myocardial fibrosis. This is the background for the development of ventricular wall stiffness and increased diastolic relaxation time which constitute the early moments of that diastolic dysfunction characterizing early stages of cardiomyopathy [88]. The accumulation of triglycerides and impaired calcium reuptake can molecularly contribute to the cardiac diastolic dysfunction $[83,87,88]$. The progression to systolic dysfunction is characterized by an eccentric (dilated) cardiac remodeling slowly progressing towards heart failure [89]. Such progression is induced by the cardiomyocytes death and their replacement with fibroblasts and interstitial fibrosis [90-92]. Such events can be detected even in researches involving humans. Although literature is poor about human protocols demonstrating the effects of pre-diabetes and diabetes on direct evidence of cardiac myocytes hypertrophy, some evidences can be outlined. De Marco et al. [93] evaluated echocardiographic data from 1624 young patients (mean age $26.6 \pm 7.7$ years) differentiating them according to glycemic condition into three groups: normal fasting glucose individuals impaired fasting glucose (pre-diabetic) subjects and diabetes patients. Their multivariate regression model pointed out that the latter two groups were formed by individuals showing left ventricular mass index (LVMI) higher than controls (diabetes LVMI: $41.5 \pm 8.7$ and prediabetes LVMI: $39.6 \pm 9.2$ vs. controls LVMI: $35.6 \pm 7.8 \mathrm{~g} / \mathrm{m} 2.7$ ) [93]. The relationship was maintained even according the prevalence of left ventricle hypertrophy among the three groups.

An elegant study from Velagaleti et al. [94] demonstrated that prediabetic and diabetic Framingham Heart Study Offspring individuals showed a direct relationship between their insulin-resistance condition and the ratio between left ventricular mass to end-diastolic volume ratio: this was expression of a concentric remodeling occurring more often in such patients than their normal counterpart [94]. Such results were prospectively demonstrated by Lee et al. [95], confirming the association between cardiac morphological alterations and prediabetic condition.

Furthermore, the toxic action of free fatty acids on mitochondrial activities leads to mitochondrial apoptosis and reduced adenosine triphosphate (ATP) bioavailability for the heart needs: this precipitates impairment in cardiac contractility and ejection fraction [96].

\section{Diagnostic evaluation of diabetic cardiomyopathy}

Several diagnostic methods can assess early moments of structural and functional cardiac alterations in diabetic patients: echocardiography, magnetic resonance image (MRI), computed tomography (CT) and positron emission tomography (PET) scans are all eligible techniques [97]. Trans-thoracic echocardiography (TTE) is not always appropriate for some categories of patients (obese, asthmatic, etc) due to the poor quality of the images obtained. MRI can be more useful because it allows visual characterization of the heart cavity, including size of the chambers, wall thickness, functionality assessment, etc [98].

Two-dimensional echocardiography [99-101] and late gadolinium (Gd) enhancement in cardiac MRI [102] easily detect interstitial fibrosis in diabetic hearts. In particular, Kwong et al. [102] observed late Gd-enhancement in MRI in $28 \%$ of diabetic patients without clinical evidence of myocardial infarction. Which of the two clinical methods is more sensitive for the detection of ventricular fibrosis in diabetic hearts remains unclear.

The most frequent early echocardiographic finding in asymptomatic diabetic patients is LV diastolic dysfunction not associated to hypertrophy $[103,104]$. Tissue Doppler imaging (TDI) is particularly sensitive in detecting left ventricle diastolic dysfunction than conventional TTE because it directly measures myocardial tissue velocities in agreement with cardiac cycle: the impairment in ventricular compliance leads to reduced myocardial tissue velocities and TDI parameters alteration. In diabetic cardiomyopathy, the E' wave is significantly lower than controls $[105,106]$. Furthermore, the evolution of diabetic cardiomyopathy is the systolic dysfunction. Several studies demonstrated reduced left ventricle fractional shortening and mid-wall shortening in diabetic subjects as compared to controls [107-109]. Furthermore, TDI researches revealed that the peak systolic velocity $\left(\mathrm{S}^{\prime}\right)$ was lower in T2D patients as compared to non-diabetic subjects, even if left ventricle ejection fraction was similar [106].

Two-dimensional speckle tracking can be employed for assessment of left ventricle systolic and diastolic dysfunction [105,110]. In particular, longitudinal strain is reduced in asymptomatic patients with uncomplicated diabetes mellitus [111,112].

\section{Conclusions}

Diabetes is a subtle disease, able to impair the clinical conditions of individuals even when it is not already expressed in its classical metabolic forms. Family history of diabetes, for example, account for an increase in cardiovascular risk of individuals even if such subjects have no sign of pre-diabetes or diabetes: the demonstration of an insulin resistance condition can account for the induction of an endothelial impairment able to enhance atherosclerotic disease.

Pre-diabetic condition is a further expression of incipient atherosclerosis development. The synergism between a systemic inflammatory condition and the presence of high blood glucose 
concentrations are the mix able to impair vascular endothelium in its function, thus predisposing to atherosclerotic lesions. Thus, all these patients should be carefully evaluated in order to detect early sign of alterations by means of all the available non-invasive techniques.

All the scientists' efforts should be addressed to the prevention of the onset of the most dangerous lesions induced by diabetes: diabetic cardiomyopathy. The enhanced oxidative stress, the increased circulating free fatty acids and the altered lipids metabolism induce heart structure damages that can lead to diabetic cardiomyopathy and that can be found by non-invasive instrumental technique. Nevertheless, the inner mechanisms underlining such progression of the cardiac damages are still not fully understood and more trials are needed.

\section{References}

1. Yach D, Stuckler D, Brownell KD (2006) Epidemiologic and economic consequences of the global epidemics of obesity and diabetes. Nat Med 12: 62-66.

2. Authors/Task Force Members, Rydén L, Grant PJ, Anker SD, Berne C, et al. (2013) ESC Guidelines on diabetes, pre-diabetes, and cardiovascular diseases developed in collaboration with the EASD: the Task Force on diabetes, pre-diabetes, and cardiovascular diseases of the European Society of Cardiology (ESC) and developed in collaboration with the European Association for the Study of Diabetes (EASD). Eur Heart J 34: 3035-3087.

3. Cersosimo E, DeFronzo RA (2006) Insulin resistance and endothelial dysfunction: the road map to cardiovascular diseases. Diabetes Metab Res Rev 22: 423-436.

4. American Diabetes Association (2014) Diagnosis and classification of diabetes mellitus. Diabetes Care 37 Suppl 1: S81-90.

5. Cowie CC, Rust KF, Ford ES, Eberhardt MS, Byrd-Holt DD, et al. (2009) Full accounting of diabetes and pre-diabetes in the U.S. population in 1988-1994 and 2005-2006. Diabetes Care 32: 287-294.

6. Harris MI, Flegal KM, Cowie CC, Eberhardt MS, Goldstein DE, et al (1998) Prevalence of diabetes, impaired fasting glucose, and impaired glucose tolerance in U.S. adults. The Third National Health and Nutrition Examination Survey, 1988-1994. Diabetes Care 21: 518-524.

7. Shah AS, Gao Z, Urbina EM, Kimball TR, Dolan LM (2014) Pre-diabetes: The Effects on Arterial Thickness and Stiffness in Obese Youth. J Clin Endocrinol Metab.

8. Tian L, Zhu J, Liu L, Liang Y, Li J, et al. (2014) Prediabetes and shortterm outcomes in nondiabetic patients after acute ST-elevation myocardial infarction. Cardiology 127: 55-61.

9. Erdogan D, Yucel H, Uysal BA, Ersoy IH, Icli A, et al. (2013) Effects of prediabetes and diabetes on left ventricular and coronary microvascular functions. Metabolism 62: 1123-1130.

10. Levitan EB, Song Y, Ford ES, Liu S (2004) Is nondiabetic hyperglycemia a risk factor for cardiovascular disease? A meta-analysis of prospective studies. Arch Intern Med 164: 2147-2155.

11. Ferrannini E, Gastaldelli A, Iozzo P (2011) Pathophysiology of prediabetes. Med Clin North Am 95: 327-339, vii-viii.

12. Campbell JE, Drucker DJ (2013) Pharmacology, physiology, and mechanisms of incretin hormone action. Cell Metab 17: 819-837.

13. Ahmadieh H, Azar ST (2014) The role of incretin-based therapies in prediabetes: A review. Prim Care Diabetes pii: S1751-9918(14)00037-0. doi: 10.1016/j.pcd.2014.02.005. [Epub ahead of print]

14. Meier JJ (2009) The contribution of incretin hormones to the pathogenesis of type 2 diabetes. Best Pract Res Clin Endocrinol Metab 23: 433-441.

15. Szmitko PE, Leiter LA, Verma S (2010) The incretin system and cardiometabolic disease. Can J Cardiol 26: 87-95.

16. He Z, King GL (2004) Microvascular complications of diabetes. Endocrinol Metab Clin North Am 33: 215-238, xi-xii.
17. Bakker W, Eringa EC, Sipkema P, van Hinsbergh VW (2009) Endothelial dysfunction and diabetes: roles of hyperglycemia, impaired insulin signaling and obesity. Cell Tissue Res 335: 165-189.

18. Koya D, Jirousek MR, Lin YW, Ishii H, Kuboki K, et al. (1997) Characterization of protein kinase $\mathrm{C}$ beta isoform activation on the gene expression of transforming growth factor-beta, extracellular matrix components, and prostanoids in the glomeruli of diabetic rats. J Clin Invest 100: 115-126.

19. Koya D, Haneda M, Nakagawa H, Isshiki K, Sato H, et al. (2000) Amelioration of accelerated diabetic mesangial expansion by treatment with a PKC beta inhibitor in diabetic $\mathrm{db} / \mathrm{db}$ mice, a rodent model for type 2 diabetes. FASEB J 14: 439-447.

20. Ciccone MM, Bilianou E, Balbarini A, Gesualdo M, Ghiadoni L, et al. (2013) Task force on: 'Early markers of atherosclerosis: influence of age and sex'. J Cardiovasc Med (Hagerstown) 14: 757-766.

21. Ciccone M, Pestrichella V, Rossi O, Maiorano A, Modugno M, et al. (1999) Oxidative stress is an early marker of endothelial dysfunction? Clin Hemorheol Microcirc 21: 341-342.

22. Azcutia V, Abu-Taha M, Romacho T, Vázquez-Bella M, Matesanz N, et al. (2010) Inflammation determines the pro-adhesive properties of high extracellular d-glucose in human endothelial cells in vitro and rat microvessels in vivo. PLoS One 5: e10091.

23. Rasmussen LM, Schmitz O, Ledet $\mathrm{T}$ (2002) Increased expression of vascular cell adhesion molecule-1 (VCAM-1) in cultured endothelial cells exposed to serum from type 1 diabetic patients: no effects of high glucose concentrations. Scand J Clin Lab Invest 62: 485-493.

24. Lucas R, Parikh SJ, Sridhar S, Guo DH, Bhagatwala J, et al. (2013) Cytokine profiling of young overweight and obese female African American adults with prediabetes. Cytokine 64: 310-315.

25. Goldberg RB (2009) Cytokine and cytokine-like inflammation markers, endothelial dysfunction, and imbalanced coagulation in development of diabetes and its complications. J Clin Endocrinol Metab 94: 3171-3182.

26. Rittig K, Peter A, Baltz KM, Tschritter O, Weigert C, et al. (2008) The CCR2 promoter polymorphism T-960A, but not the serum MCP-1 level, is associated with endothelial function in prediabetic individuals. Atherosclerosis 198: 338-346.

27. Konukoglu D, Firtina S, Serin O (2008) The relationship between plasma asymmetrical dimethyl-L-arginine and inflammation and adhesion molecule levels in subjects with normal, impaired, and diabetic glucose tolerance. Metabolism 57: 110-115.

28. Brownlee M (2001) Biochemistry and molecular cell biology of diabetic complications. Nature 414: 813-820.

29. Tapp RJ, Shaw JE, Zimmet PZ, Balkau B, Chadban SJ, et al. (2004) Albuminuria is evident in the early stages of diabetes onset: results from the Australian Diabetes, Obesity, and Lifestyle Study (AusDiab). Am J Kidney Dis 44: 792-798.

30. Yudkin JS, Stehouwer CD, Emeis JJ, Coppack SW (1999) C-reactive protein in healthy subjects: associations with obesity, insulin resistance, and endothelial dysfunction: a potential role for cytokines originating from adipose tissue? Arterioscler Thromb Vasc Biol 19: 972-978.

31. Pasceri V, Willerson JT, Yeh ET (2000) Direct proinflammatory effect of C-reactive protein on human endothelial cells. Circulation 102: 2165-2168.

32. Festa A, D'Agostino R Jr, Tracy RP, Haffner SM; Insulin Resistance Atherosclerosis Study (2002) Elevated levels of acute-phase proteins and plasminogen activator inhibitor-1 predict the development of type 2 diabetes. The Insuline Resistance Atherosclerosis Study. Diabetes 51: 1131-1137.

33. Flammer AJ, Gössl M, Li J, Matsuo Y, Reriani M, et al. (2012) Patients with an HbAlc in the prediabetic and diabetic range have higher numbers of circulating cells with osteogenic and endothelial progenitor cell markers. J Clin Endocrinol Metab 97: 4761-4768.

34. Dean JD, Jones CJ, Hutchison SJ, Peters JR, Henderson AH (1991) Hyperinsulinaemia and microvascular angina ("syndrome X") Lancet 337: 456-457. 
35. Han KA, Patel Y, Lteif AA, Chisholm R, Mather KJ (2011) Contributions of dysglycaemia, obesity, and insulin resistance to impaired endotheliumdependent vasodilation in humans. Diabetes Metab Res Rev 27: 354-361.

36. Liu Y, Li J, Zhang Z, Tang Y, Chen Z, et al. (2014) Endocrinological analysis of endothelium-dependent vasodilation in middle-aged patients with impaired glucose tolerance during prediabetes mellitus. Exp Ther Med 7: 697-702.

37. Su Y, Liu XM, Sun YM, Jin HB, Fu R, et al. (2008) The relationship between endothelial dysfunction and oxidative stress in diabetes and prediabetes. Int J Clin Pract 62: 877-882.

38. Ciccone MM, Balbarini A, Teresa Porcelli M, Santoro D, Cortese F, et al (2011) Carotid artery intima-media thickness: normal and percentile values in the Italian population (camp study). Eur J Cardiovasc Prev Rehabil 18: 650-655.

39. De Pergola G, Ciccone M, Pannacciulli N, Modugno M, Sciaraffia M, et al. (2000) Lower insulin sensitivity as an independent risk factor for carotid wall thickening in normotensive, non-diabetic, non-smoking normal weight and obese premenopausal women. Int J Obes Relat Metab Disord 24: 825-829.

40. Parildar H, Gulmez O, Cigerli O, Dogruk Unal A, Erdal R, et al. (2013) Carotid Artery Intima Media Thickness and HsCRP; Predictors for Atherosclerosis in Prediabetic Patients? Pak J Med Sci 29: 495-499.

41. Faeh D, William J, Yerly P, Paccaud F, Bovet P (2007) Diabetes and prediabetes are associated with cardiovascular risk factors and carotid/ femoral intima-media thickness independently of markers of insulin resistance and adiposity. Cardiovasc Diabetol 6: 32.

42. Shen L, Zhang YG, Liu M, Qiang DC, Sun XL, et al. (2013) Increased arterial stiffness in subjects with pre-diabetes among middle aged population in Beijing, China. Biomed Environ Sci 26: 717-725.

43. Shin JY, Lee HR, Lee DC (2011) Increased arterial stiffness in healthy subjects with high-normal glucose levels and in subjects with prediabetes. Cardiovasc Diabetol 10: 30.

44. Cherian S, Roy S, Pinheiro A, Roy S (2009) Tight glycemic control regulates fibronectin expression and basement membrane thickening in retinal and glomerular capillaries of diabetic rats. Invest Ophthalmol Vis Sci 50: 943-949.

45. Shurter A, Genter P, Ouyang D, Ipp E (2013) Euglycemic progression: worsening of diabetic retinopathy in poorly controlled type 2 diabetes in minorities. Diabetes Res Clin Pract 100: 362-367.

46. Chilelli NC, Burlina S, Lapolla A (2013) AGEs, rather than hyperglycemia, are responsible for microvascular complications in diabetes: a "glycoxidation-centric" point of view. Nutr Metab Cardiovasc Dis 23: 913-919.

47. Stratton IM, Adler AI, Neil HA, Matthews DR, Manley SE, et al. (2000) Association of glycaemia with macrovascular and microvascular complications of type 2 diabetes (UKPDS 35): prospective observational study. BMJ 321: 405-412.

48. DCCT/EDIC Research Group, de Boer IH, Sun W, Cleary PA, Lachin JM, et al. (2011) Intensive diabetes therapy and glomerular filtration rate in type 1 diabetes. $\mathrm{N}$ Engl J Med 365: 2366-2376.

49. Control Group, Turnbull FM, Abraira C, Anderson RJ, Byington RP, et al. (2009) Intensive glucose control and macrovascular outcomes in type 2 diabetes. Diabetologia 52: 2288-2298.

50. Balkau B, Shipley M, Jarrett RJ, Pyörälä K, Pyörälä M, et al. (1998) High blood glucose concentrations is a risk factor for mortality in middle-aged nondiabetic men. 20-year follow-up in the Whitehall Study, the Paris Prospective Study, and the Helsinki Policemen Study. Diabetes Care 21: 360-3677

51. Jaap AJ, Hammersley MS, Shore AC, Tooke JE (1994) Reduced microvascular hyperaemia in subjects at risk of developing type 2 (noninsulin-dependent) diabetes mellitus. Diabetologia 37: 214-216.

52. Williams SB, Goldfine AB, Timimi FK, Ting HH, Roddy MA, et al. (1998) Acute hyperglycemia attenuates endothelium-dependent vasodilation in humans in vivo. Circulation 97: 1695-1701.
53. Kriketos AD, Greenfield JR, Peake PW, Furler SM, Denyer GS, et al. (2004) Inflammation, insulin resistance, and adiposity: a study of firstdegree relatives of type 2 diabetic subjects. Diabetes Care 27: 2033-2040.

54. Newman B, Selby JV, King MC, Slemenda C, Fabsitz R, et al. (1987) Concordance for type 2 (non-insulin-dependent) diabetes mellitus in male twins. Diabetologia 30: 763-768.

55. Eriksson J, Franssila-Kallunki A, Ekstrand A, Saloranta C, Widén E, et al. (1989) Early metabolic defects in persons at increased risk for noninsulin-dependent diabetes mellitus. N Engl J Med 321: 337-343.

56. Straczkowski M, Kowalska I, StepieÅ, A, Dzienis-Straczkowska S Szelachowska M, et al. (2003) Insulin resistance in the first-degree relatives of persons with type 2 diabetes. Med Sci Monit 9: CR186-190.

57. Potenza MA, Addabbo F, Montagnani M (2009) Vascular actions of insulin with implications for endothelial dysfunction. Am J Physiol Endocrinol Metab 297: E568-577.

58. Kim JA, Montagnani M, Koh KK, Quon MJ (2006) Reciprocal relationships between insulin resistance and endothelial dysfunction: molecular and pathophysiological mechanisms. Circulation 113: 1888-1904.

59. Balletshofer BM, Rittig K, Enderle MD, Volk A, Maerker E, et al. (2000) Endothelial dysfunction is detectable in young normotensive first-degree relatives of subjects with type 2 diabetes in association with insulin resistance. Circulation 101: 1780-1784.

60. Goldfine AB, Beckman JA, Betensky RA, Devlin H, Hurley S, et al. (2006) Family history of diabetes is a major determinant of endothelial function. J Am Coll Cardiol 47: 2456-2461.

61. Scuteri A, Tesauro M, Rizza S, Iantorno M, Federici M, et al. (2008) Endothelial function and arterial stiffness in normotensive normoglycemic forst-degree relatives of diabetic patients are independent of the metabolic syndrome. Nutr Metab Cardiovasc Dis 18: 349-456.

62. Lee BC, Shore AC, Humphreys JM, Lowe GD, Rumley A, et al. (2001) Skin microvascular vasodilatory capacity in offspring of two parents with Type 2 diabetes. Diabet Med 18: 541-545.

63. Hopkins KD, Lehmann ED, Jones RL, Turay RC, Gosling RG (1996) A family history of NIDDM is associated with decreased aortic distensibility in normal healthy young adult subjects. Diabetes Care 19: 501-503.

64. Pannacciulli N, De Pergola G, Ciccone M, Rizzon P, Giorgino F, et al. (2003) Effect of family history of type 2 diabetes on the intima-media thickness of the common carotid artery in normal-weight, overweight, and obese glucose-tolerant young adults. Diabetes Care 26: 1230-1234.

65. Anderwald C, Stadler M, Golay A, Krebs M, Petrie J, et al. (2010) Impact of family history on relations between insulin resistance, LDL cholesterol and carotid IMT in healthy adults. Heart 96: 1191-1200.

66. Anderwald C, Pfeiler G, Nowotny P, Anderwald-Stadler M, Krebs M, et al. (2008) Glucose turnover and intima media thickness of internal carotid artery in type 2 diabetes offspring. Eur J Clin Invest 38: 227-237.

67. Ahmad J, Ahmed F, Siddiqui MA, Hameed B, Ahmad I (2006) Inflammation, insulin resistance and carotid IMT in first degree relatives of north Indian type 2 diabetic subjects. Diabetes Res Clin Pract 73: 205-210.

68. Eschwege E, Richard JL, Thibult N, Ducimetière P, Warnet JM, et al. (1985) Coronary heart disease mortality in relation with diabetes, blood glucose and plasma insulin levels: the Paris prospective study, ten years later. Horm Metab Res 15: 41-46.

69. Groop L, Forsblom C, Lehtovirta M, Tuomi T, Karanko S, et al. (1996) Metabolic consequences of a family history of NIDDM (the Botnia study): evidence for sex-specific parental effects. Diabetes 45: 1585-1593.

70. Sarlund H, Pyörälä K, Penttilä I, Laakso M (1992) Early abnormalities in coronary heart disease risk factors in relatives of subjects with noninsulin-dependent diabetes. Arterioscler Thromb 12: 657-663.

71. Gürlek A, Bayraktar M, Kirazli S (2000) Increased plasminogen activator inhibitor-1 activity in offspring of type 2 diabetic patients: lack of association with plasma insulin levels. Diabetes Care 23: 88-92. 
72. Allcock DM, Sowers JR (2010) Best strategies for hypertension management in type 2 diabetes and obesity. Curr Diab Rep 10: 139-144.

73. Selvin E, Steffes MW, Zhu H, Matsushita K, Wagenknecht L, et al. (2010) Glycated hemoglobin, diabetes, and cardiovascular risk in nondiabetic adults. N Engl J Med 362: 800-811.

74. Rubler S, Dlugash J, Yuceoglu YZ, Kumral T, Branwood AW, et al. (1972) New type of cardiomyopathy associated with diabetic glomerulosclerosis. Am J Cardiol 30: 595-602.

75. Aneja A, Tang WH, Bansilal S, Garcia MJ, Farkouh ME (2008) Diabetic cardiomyopathy: insights into pathogenesis, diagnostic challenges, and therapeutic options. Am J Med 121: 748-757.

76. Calle MC, Fernandez ML (2012) Inflammation and type 2 diabetes. Diabetes Metab 38: 183-191.

77. Miranville A, Herling AW, Biemer-Daub G, Voss MD (2012) Differential adipose tissue inflammatory state in obese nondiabetic Zucker fatty rats compared to obese diabetic zucker diabetic fatty rats. Horm Metab Res 44: 273-278.

78. Pulakat L, DeMarco VG, Ardhanari S, Chockalingam A, Gul R, et al. (2011) Adaptive mechanisms to compensate for overnutrition-induced cardiovascular abnormalities. Am J Physiol Regul Integr Comp Physiol 301: R885-895.

79. Iliadis F, Kadoglou N, Didangelos T (2011) Insulin and the heart Diabetes Res Clin Pract 93 Suppl 1: S86-91.

80. Hitomi H, Mehta PK, Taniyama $\mathrm{Y}$, Lassègue B, Seidel-Rogol B, et al. (2011) Vascular smooth muscle insulin resistance, but not hypertrophic signaling, is independent of angiotensin II-induced IRS-1 phosphorylation by JNK. Am J Physiol Cell Physiol 301: C1415-1422.

81. Yang J, Park Y, Zhang H, Xu X, Laine GA, et al. (2009) Feed-forward signaling of TNF-alpha and NF-kappaB via IKK-beta pathway contributes to insulin resistance and coronary arteriolar dysfunction in type 2 diabetic mice. Am J Physiol Heart Circ Physiol 296: H1850-1858.

82. Aroor AR, Mandavia CH, Sowers JR (2012) Insulin resistance and heart failure: molecular mechanisms. Heart Fail Clin 8: 609-617.

83. Zhang $X$, Chen $C$ (2012) A new insight of mechanisms, diagnosis and treatment of diabetic cardiomyopathy. Endocrine 41: 398-409.

84. Aksakal E, Akaras N, Kurt M, Tanboga IH, Halici Z, et al. (2011) The role of oxidative stress in diabetic cardiomyopathy: an experimental study. Eur Rev Med Pharmacol Sci 15: 1241-1246.

85. Watanabe K, Thandavarayan RA, Harima M, Sari FR, Gurusamy N, et al. (2010) Role of differential signaling pathways and oxidative stress in diabetic cardiomyopathy. Curr Cardiol Rev 6: 280-290.

86. Maisch B, Alter P, Pankuweit S (2011) Diabetic cardiomyopathy--fact or fiction? Herz 36: 102-115.

87. Mandavia CH, Pulakat L, DeMarco V, Sowers JR (2012) Over-nutrition and metabolic cardiomyopathy. Metabolism 61: 1205-1210.

88. D'Souza A, Howarth FC, Yanni J, Dobryznski H, Boyett MR, et al. (2011) Left ventricle structural remodelling in the prediabetic Goto-Kakizaki rat. Exp Physiol 96: 875-888.

89. Hayden MR, Tyagi SC (2003) Myocardial redox stress and remodeling in metabolic syndrome, type 2 diabetes mellitus, and congestive heart failure. Med Sci Monit 9: SR35-52.

90. Booz GW, Baker KM (1995) Molecular signalling mechanisms controlling growth and function of cardiac fibroblasts. Cardiovasc Res 30: 537-543.

91. Rude MK, Duhaney TA, Kuster GM, Judge S, Heo J, et al. (2005) Aldosterone stimulates matrix metalloproteinases and reactive oxygen species in adult rat ventricular cardiomyocytes. Hypertension 46: 555-561.

92. Schreier B, Rabe S, Schneider B, Ruhs S, Grossmann C, et al. (2011) Aldosterone/ $\mathrm{NaCl}$-induced renal and cardiac fibrosis is modulated by TGF- $\hat{I}^{2}$ responsiveness of T cells. Hypertens Res 34: 623-629.

93. De Marco M, de Simone G, Roman MJ, Chinali M, Lee ET, et al. (2011) Cardiac geometry and function in diabetic or prediabetic adolescents and young adults: the Strong Heart Study. Diabetes Care 34: 2300-2305.
94. Velagaleti RS, Gona P, Chuang ML, Salton CJ, Fox CS, et al. (2010) Relations of insulin resistance and glycemic abnormalities to cardiovascular magnetic resonance measures of cardiac structure and function: the Framingham Heart Study. Circ Cardiovasc Imaging 3: $257-263$

95. Lee S, Cowan PA, Wetzel GT, Velasquez-Mieyer P (2011) Prediabetes and blood pressure effects on heart rate variability, QT-interval duration, and left ventricular hypertrophy in overweight-obese adolescents. J Pediatr Nurs 26: 416-427.

96. Boudina S, Sena S, Theobald H, Sheng X, Wright JJ, et al. (2007) Mitochondrial energetics in the heart in obesity-related diabetes: direct evidence for increased uncoupled respiration and activation of uncoupling proteins. Diabetes 56: 2457-2466.

97. Jellis C, Wright J, Kennedy D, Sacre J, Jenkins C, et al. (2011) Association of imaging markers of myocardial fibrosis with metabolic and functional disturbances in early diabetic cardiomyopathy. Circ Cardiovasc Imaging 4: 693-702.

98. O'Donnell DH, Abbara S, Chaithiraphan V, Yared K, Killeen RP, et al (2012) Cardiac MR imaging of nonischemic cardiomyopathies: imaging protocols and spectra of appearances. Radiology 262: 403-422.

99. Picano E, Pelosi G, Marzilli M, Lattanzi F, Benassi A, et al. (1990) In vivo quantitative ultrasonic evaluation of myocardial fibrosis in humans. Circulation 81: 58-64.

100. Pérez JE, McGill JB, Santiago JV, Schechtman KB, Waggoner AD, et al. (1992) Abnormal myocardial acoustic properties in diabetic patients and their correlation with the severity of disease. J Am Coll Cardiol 19: 1154-1162.

101. Di Bello V, Talarico L, Picano E, Di Muro C, Landini L, et al. (1995) Increased echodensity of myocardial wall in the diabetic heart: an ultrasound tissue characterization study. J Am Coll Cardiol 25: 1408-1415.

102. Kwong RY, Sattar H, Wu H, Vorobiof G, Gandla V, et al. (2008) Incidence and prognostic implication of unrecognized myocardial scar characterized by cardiac magnetic resonance in diabetic patients without clinical evidence of myocardial infarction. Circulation 118: 1011-1020.

103. Schannwell CM, Schneppenheim M, Perings S, Plehn G, Strauer BE (2002) Left ventricular diastolic dysfunction as an early manifestation of diabetic cardiomyopathy. Cardiology 98: 33-39.

104. Ha JW, Lee HC, Kang ES, Ahn CM, Kim JM, et al. (2007) Abnormal left ventricular longitudinal functional reserve in patients with diabetes mellitus: implication for detecting subclinical myocardial dysfunction using exercise tissue Doppler echocardiograpjhy. Heart 93: 1571-1576.

105. Kosmala W, Kucharski W, Przewlocka-Kosmala M, Mazurek W (2004) Comparison of left ventricular function by tissue Doppler imaging in patients with diabetes mellitus without systemic hypertension versus diabetes mellitus with systemic hypertension. Am J Cardiol 94: 395-399.

106. Di Bonito P, Moio N, Cavuto L, Covino G, Murena E, et al. (2005) Early detection of diabetic cardiomyopathy: usefulness of tissue Doppler imaging. Diabet Med 22: 1720-1725.

107. Devereux RB, Roman MJ, Paranicas M, O'Grady MJ, Lee ET, et al. (2000) Impact of diabetes on cardiac structure and function: the strong heart study. Circulation 101: 2271-2276.

108. Bella JN, Devereux RB, Roman MJ, Palmieri V, Liu JE, et al. (2001) Separate and joint effects of systemic hypertension and diabetes mellitus on left ventricular structure and function in American Indians (the Strong Heart Study). Am J Cardiol 87: 1260-1265.

109. Heckbert SR, Post W, Pearson GD, Arnett DK, Gomes AS, et al. (2006) Traditional cardiovascular risk factors in relation to left ventricular mass, volume, and systolic function by cardiac magnetic resonance imaging: the Multiethnic Study of Atherosclerosis. J Am Coll Cardiol 48: 2285-2292.

110. Andersen NH, Poulsen SH, Eiskjaer H, Poulsen PL, Mogensen CE (2003) Decreased left ventricular longitudinal contraction in normotensive and normoalbuminuric patients with type II diabetes mellitus: a Doppler tissue tracking and strain rate echocardiography study. Clin Sci (Lond) 105: 59-66. 
Citation: Ciccone MM, Scicchitano P, Cameli M, Cecere A, Cortese F, et al. (2014) Endothelial Function in Pre-diabetes, Diabetes and Diabetic Cardiomyopathy: A Review. J Diabetes Metab 5: 364. doi:10.4172/2155-6156.1000364

Page 10 of 10

111. Ng AC, Delgado V, Bertini M, van der Meer RW, Rijzewijk LJ, et al (2009) Findings from left ventricular strain and strain rate imaging in asymptomatic patients with type 2 diabetes mellitus. Am J Cardiol 104: 1398-1401.
112. Ernande L, Rietzschel ER, Bergerot C, De Buyzere ML, Schnell F, et al. (2010) Impaired myocardial radial function in asymptomatic patients with type 2 diabetes mellitus: a speckle-tracking imaging study. J Am Soc Echocardiogr 23: 1266-1272. 